\title{
Understanding International Business in the Context of Cultural Lenses
}

\author{
Tega Douborapade Ogbuigwe (Mrs.) \\ Department of Management, Faculty of Management Sciences, Rivers State University of Science \& \\ Technology, Port-Harcourt, Rivers State, Nigeria.
}

\begin{abstract}
This paper is based on the premise that for business organizations to succeed in our globalized, competitive international environment without a 'globalized' culture, business managers need to have a sound and practical knowledge of cross boarder cultures. Believing, as Dewey (1938) long ago recognized that "there is nothing more practical than a good theory", the paper identified from the professional literature and discussed seven theories of culture. The understanding of these cultural models would help the business manager to become more intelligent, culturally more sensitive to cultural differences, develop cultural competence and became more effective and efficient as he/she works to overcome cultural complexities that can negatively affect business and business profits.
\end{abstract}

Keywords: Cultural dimensions, cultural lenses, cultural models, cultural sensitivity, international business management, national cultures, theories of national cultures

\section{Introduction}

Today, the world is becoming a one "big village" than ever before because of "smart" technology. As a result of competition, business owners and / or operators have also increasingly found the need to do business across their own national boundaries. While the world is becoming globalized there is yet to emerge a "global" culture and a common business culture is yet to exist. We do know that national culture has implications for and do impact on business profit (Peretomode, 2012), management strategies, relationships, communication, international commerce and investment, marketing, consumer behaviour and advertising issues.

From the above observations, it can be argued that in order to survive or succeed in this globalised, competitive international environment, multinationals and international business managers need to have a practical and sound understanding of cross - border cultures. Inability to be culturally sensitive and culturally competent may lead to business failure and avoidable wastage of funds. Five brief illustrative cases below by Kwintessential Ltd (2012) drives home the point:

- The concept of Big Brother was somehow taken to the Middle East. After funds have been spent on advertising, the show was pulled off the air after its first few episodes due to public protests and pressure from religious bodies stating that the show's mixed sex format was against Islamic Principles.

- Pepsodent tried to sell its toothpaste in South East Asia by emphasizing that it "whitens your teeth". They found out that the local natives chew betel nuts to blacken their teeth which they find attractive.

- A new facial cream with the name "Joni" was proposed for marketing in India. They changed the name since the word translated in Hindu meant "female genitals".

- Coors (beer) had its Slogan, "Turn it loose," translated into Spanish, where it became suffer from diarrhea", and

- The fast food giant, McDonald, spent thousands of dollars on a new TV ad to target the Chinese consumer. The ad showed a Chinese man kneeling before a McDonald's Vendor and begging him to accept his expired discount coupon. The ad was pulled due to lack of cultural understanding and sensitivity on McDonald's behalf. The ad caused uproar over the fact that begging is considered a shameful act in Chinese culture (http://www kwintessential.co.uk/cultural-services/articles/cultural-sensitivity.html. (10/07/2012).

The above cases vividly point to the necessity for international business managers to have an in-depth knowledge and understanding of national cultural differences (lenses) as an asset. As UNFPA (2013) rightly pointed out, a cultural lens clarifies:

- The realities and socio-cultural assets of societies.

- The influential power structures and pressure groups that can be potential allies or adversaries to management, and

- The internal cultural tensions and aspirations of the various sub-cultures.

One way to achieve the above is through the knowledge of cultural models and theories or cultural backgrounds (lenses) of communities and their similarities. It is also critical to understand the role that experience, cultural 
intelligence and expertise, awareness and sensitivity can play in order for the international business manager to have an advantage and be successful as he works to overcome cultural complexities that can negatively affect business. These are the objectives this article attempts to address. First is an identification, analysis and integration of some of the cultural models and theories.

\section{Models and Theories of National Culture}

Specialists in business and management have established vast literatures on cultural models and theories which are still increasing in number. They are scattered and some are applicable in international business and management. Seven of such models / theories have been identified to serving as fundamentals and stepping stone to understanding culture in the context of international business (Singh. 2002). Each of these models/theories will be reviewed and analyzed and attempt made to highlight some of their similarities. The implications of each of these models would also be highlighted. The seven models/theories of national culture that will be examined are:

1. Edward T. Hall's Cultural continuum

2. Trompenaars and Hampden - Turner cultural dimensions.

3. Hofstede's Dimensions of work- related values

4. Zbigniew T. Rurak dualities cultural model

5. The Ice - berg Model of Culture

6. Kluckholn and Strodtbeck Cultural Orientations Framework

7. Milton Bennett's Developmental Model of cultural sensitivity.

In discussing theories and models of culture, the phrase "dimension of culture" is always used. Therefore a proper understanding of what this means is important. Hofstede (1995:23) defines dimension as "an aspect of culture that can be measured relative to other cultures".

\section{Edward T. Hall's Cultural Continuum}

Edward T. Hall (1976) proposed a model in which cultures are placed on a continuum of high versus low context approach to life. In this model, he explained that no culture necessarily lays on either extreme of the continuum but cultures are relatively high or low in relation to the characteristics both ends of the continuum possess (Mead and Andrew 2009). High context cultures are cultures where people are closely involved with each other and a strong bond exists that extends from family to friends and society in general and as a result there is free and unrestricted flow of information (Hall 1976 and Kim et al, 1998). On the other hand, a low context culture is one in which people are highly individualized, somewhat alienated and fragmented and there is relatively little involvement with others" (Hall 1976:39). And Kim et al. (1998), in an attempt to give a detailed analysis of Hall's theory, discussed high and low context under five aspects;

i. Social orientation: According to Kim et al (1998), a high context culture tends to be collectivistic in nature. People are closely related and share detailed information and this is evident in the business practices of high context cultures as they rely on relationship and connection to succeed. Hall (1990) had explained that in high context cultures, employees are well informed on all aspects of the business as businesses are devoted to the gathering, analysis and dissemination of information. On the other hand, Kim et al (1998) explains that in low context cultures, the social ties are weak and people tend to do things on their own and information sharing is kept to the minimal. In a business environment, this can lead to constant competition between employees in an organization, as everyone will be striving to know something else no one else knows.

ii. Commitment: In high context culture, there exists high levels of commitment amongst members of the society as existing tight bonds bring about cohesion and dependence on each other (Kim et al 1998). In such cultures, business agreements are usually spoken than written as people are expected to do as they say (Mead and Andrews, 2009, Kim et al 1998). On the other hand, low context cultures people do not feel the need to be committed to others as they are already individualistic and depend on themselves.

iii. Responsibility: According to Hall (1976: 113), in high context cultures,"people in places of high authority are personally and truly (not just in theory) responsible for the actions of subordinates down to the last man". In a business environment, this can make managers and superior ensure that their work gets done as they know failure to meet objectives will be punishable to them. On the other hand, in low context cultures, identifying who is responsible for certain activities is difficult and should an error occur subordinates are likely to take the fall.

iv. Confrontation: Members of a high context culture will do anything to avoid direct confrontation and are expected to have self control and hide inner feelings regardless of what their feelings are about certain 
situations (Hall, 1976). This can be equated to face saving, according to Tse et al (1988), where it is the responsibility of an individual to maintain dignity even in trivial matters. Kim et al. (1998) explained that the implication of such behavior is that people tend to repress self feelings in order to maintain harmony which in the short run works and has its benefits but over time leads to disputes that are sometimes insignificant as a result of bottled anger. Kim et al. (1998) also explained that in low context cultures freedom to express and define one's self is more accepted as a way of creating harmony. Therefore, direct confrontation is not frowned upon and perceived more easily when approaching.

v. Communication: Communication is quick and well organized in high context cultures as less is verbally expressed and emphasis is put on the meanings and understanding that can be drawn (Hall 1976). On the contrary, Low context cultures communicate most of their information verbally and emphasis is put on what is said and not how it is said (Hall 1976 ; Onkvisit and Shaw 1993). Therefore, people from high context cultures will feel that low context culture people are giving too much unnecessary information and low context culture will feel lost when people from high context culture do not give enough information (Hall 1990).

\section{Trompenaars And Hampden - Turner's Cultural Dimensions}

In their 1997 book, "Riding the waves of culture", Trompenaars and Hampden - Turner developed a model consisting of seven dimensions of culture. The model recognized cultural diversity - differences in national cultures. The authors believed that the manner people responded to certain basic questions which they referred to as dilemmas was a reflection of their unique culture. Five of these dimensions analyzed relationships with people while the other two are focused on orientation to time and attitude towards the environment. Overtime, the dimensions have passed through a series of changes (Duanmu and Geppert, 2009). These dimensions are discussed briefly below:

i. Universalism vs. Particularism: (What is more important - rules or relationships?). This dimension identifies two distinct ways in which we judge people and our interpersonal behaviour and the degree of importance a culture assigns to either the law or to personal relationship. In Universalistic Culture people share the belief that general rules, codes, values, obligations and standards take precedence over the needs and claims of friends and other relationships. They try to deal with people fairly by applying the same rules across the board, in all situations - regardless of circumstances or particular situations. What is right is always right in every situation and for everybody and therefore can be applied universally. In Particularistic Culture, on the other hand, people make judgments based on their particular relationships. People see culture in terms of human friendship and intimate relationships and the rules that exist are merely to codify how people relate to one another. Therefore, what is right in one situation may not be right in another because behaviour depends on the circumstances; no one is seen as the same, everyone is treated as unique (Trompenaars and Hampden - Turner, 1997). Therefore, unique circumstances determine what is right or good.

In relating this dimension to international business, it can be argued that in a Universal culture, less emphasis is placed on personalities. Contractual agreement determines a person's behaviour and complete professionalism and logical thinking should determine business decisions (Smith and Dugan, 1996; Duanmu and Geppert, 2009). In particularist cultures, obligations to relationships are valued and such relationship can provide a basis for bending of existing rules and regulations, such that your love or hatred for someone determines whether or not you will discount, protect or sustain this person irrespective of what the law says (Trompenaars and Hampden - Turner, 1997).

ii. Individualism vs. Collectivism (Communitarianism) (Do we function as a group or as individuals?). In the individualist culture, people believe in personal freedom and achievement and that the individual should make his/her own decisions. Emphasis is placed on the individual's wants, happiness, fulfillment, initiative, benefits, and welfare above that of the group or community. On the other hand, in communitarian culture, the people decide based on the greater good irrespective of individual desires. People place the community before and / or above the individual (Trompenaars and Hampden - Turner, 1997).

iii. Specific vs. diffused: (How separate do we keep our private and working lives?). In specific - oriented cultures, people keep work and personal or private parts of their lives separate from the public. They believe that people can work together without having a good relationship. In diffused cultures, people see an overlap between their work and personal life. They believe that good relationships are vital to meeting business objective. In the business context, managers from "specific" cultures will categorize their dealings with subordinates based on task, units or points and make activities private to each of these specific categories 
(Trompenaars and Hampden - Turner, 1997). On the other hand, managers from "diffused" cultures will treat subordinates as one general group irrespective of their job specifications.

iv. Achievement vs. Ascription (How we accord status). This dimension identifies how power and status are determined in societies in relation to what someone does or what some one is (Hoecklin, 1995). It addresses the question, do we have to prove ourselves to achieve status, or is status given to us? In achievement oriented cultures, people value performance no matter who you are and status is accorded on the basis of performance and achievements such as education, ability, professional qualification, competition and so on. But in ascription - oriented cultures, status is not based on achievements but ascribed to individuals due to social connections, age or gender, origin or religion of the individuals (Smith and Dugan, 1996; Duanmu and Gepper, 2009, Trompenaars and Hampden - Turner 1997).

In a business context, achievement oriented cultures evaluate employees based on their allocated functions and employees expect to be compared with fellow employees in the same field (Hoecklin, 1995). On the other hand, ascription oriented cultures will evaluate employees on the basis of natural admiration and characteristics that draw people to them and how much loyalty they show in return (Hoecklin, 1995).

v. Neutral vs. Affective (Emotions): This dimension focuses on the degree to which people display emotions or hides them. In a neutral culture, people hide their emotions because they are taught not to overtly show their feelings. While emotions are felt, they are carefully controlled and subdued. In emotional cultures, people display their emotions plainly. It is not deemed necessary to hide feelings and so people find ways to express them, for example by laughing, smiling, grimacing, gesturing etc.

vi. Time Orientation: Sequential Vs Synchronic (Do we do things one at a time or several things at once?) This dimension shows two contrasting images about the concept of time where one perceives time as linear or sequential and the other perceives time as cyclical or synchronic with both notions having an impact on how these cultures will plan, coordinate and organize activities (Duanmu and Geppert, 2009). Cultures that conceive time as sequential believe there is time and place for everything and rely on strict and particular orders in getting things done such that a change in the established sequence of things and activities will cause uncertainty (Trompenaars and Hampden - Turner, 1997). In this culture, therefore, people like staying on schedule and do things one at a time. In contrast, in a Synchronic culture, people believe that experiences in life are as a result of an interconnection between the past, present and future and therefore do not focus on one established way of getting things done as they believe there are numerous and possible combinations of achieving objectives. Therefore, they do several things at once believing time to be flexible and intangible (Hampden - Tuner and Trompenaars 2012).

vii.Inner - Directed Orientation Vs Outer - Directed orientation (Do we control our environment or are controlled by it?). This dimension is about cultures and their attitude these Orientations (Inner - Directed ) is also called internal towards nature. The first of people have a mechanistic view of nature, that although nature is complex, in iner - directed culture, the right expertise. People believe that humans can dominate nature, control and subdue their environment to achieve set goals. In contrast, people in outer- directed cultures have an organic view of nature. They view mankind as one of nature's forces and therefore should live in harmony with the environment. People, therefore, should adapt themselves to external circumstances and actions and decisions should be determined by signals from nature or trends in the outside world (Duanmu and Geppert 2009). In Outer - directed oriented cultures, people are therefore, sometimes slow to taking decisions as they tend to search for an existing evidence or reassurance before making decisions.

\section{Hofstede's Dimension Of Work - Related Values}

This is the most widely known and cited research in comparing national cultures and how their diversity can affect behaviour in the work place (Hoecklin, 1995 and Izeremes at el, 2008). The model was the product of two researches that Hofstede conducted based on IBM - an American multinational and its subsidiaries from over 50 countries between the 1960s and early 1970s. Hofstede aimed to identify elements of cultural systems that have an impact on behaviors at work (Firoz et al. 2002). The original theory proposed four dimensions regarding four anthropological problem areas that different national societies handle namely ways of copying with inequality, uncertainty, the relationship of the individual with his / her primary group, and the emotional implications of being born a girl or a boy. And these corresponded to the following dimensions, power distance, uncertainty avoidance, individualism Vs 
collectivism, masculinity Vs feminity, respectively. Hofstede's earlier five dimensions are described and analyzed below:.

\section{i. Power Distance (PDI)}

Inequality exists in every society which may arise due to differences in legal rights, wealth, social status, education etc (Andres and Mead, 2009). Power distance is "the extent to which the less powerful members of institutions and organizations within a country expect and accept that power is distributed unequally" (Hofstede, 1991:262). Or it is the degree of inequality among people which the population of a country considers normal from relatively equal (that is, small power distance) to extremely unequal (Larger power) distance (Hofstede, 1993:89). Or simply put, power distance refers to how members of a national culture cope with inequalities and the effect it has on the work environment (Andrews and Mead, 2009). Power distance may be low or high and in the business environment, the power distance will determine the extent to which employees will accept the opinion of their superiors as right because he or she is the boss (Hoecklin, 1995).

According to Hofstede (2005), cultures that endorse low power distance expect and accept power relations that are decentralized, consultative or democratic. People relate to one another more as equals regardless of formal positions. As a result, subordinates can demand the right to contribute to and / or critique the decision making of those in power. Organizational structures are flat which creates room for free flow of information (Hecklin, 1995, Duanmu and Geppert, 2009). In high power distance cultures, on the other hand, there is a high degree of power centralization and the less powerful accept power

relations that are more autocratic and paternalistic. Therefore, employees will depend on superiors to tell them what to do and are less likely to contradict the opinion of their superiors (Hofstede, 2005). Organizational structures are tall and hierarchial which reflects the existing power distance between the top and bottom (Duanmu and Geppert, 2009).

\section{ii. Uncertainty Avoidance (UAI)}

The future is unknown and humans need to live with that anyway, which leads to uncertainty, anxiety, and the need to avoid the unknown among members of the society. The degree to which people in a country "preferred structure over unstructured situations" or the extent of a society's "tolerance for uncertainty and ambiguity is referred to as uncertainty avoidance. It reflects the extent to which members of a society are threatened by uncertain and unknown situations and attempt to cope with the associated anxiety by minimizing uncertainty (Hofstede, 1991, 2005). Cultures may implement mechanisms such as provision of long term career prospects, establishment of formal rules and regulations, rejection of ideas that are different, attainment of professional expertise in order to stabilize such uncertainties (Modern, 1995).

In high uncertainty avoidance cultures, people tend to be more emotional, they try to minimize the occurrence of unknown and unusual circumstances. They, therefore, proceed with careful changes step by step by planning and by implementing established written rules, laws and regulations. In business, there is strong loyalty to employers and employees fear to break company rules as they are more comfortable with long term relationships and resistance to change (Firoz et al, 2012). In contrast, in low uncertainty

avoidance cultures, employees are less hesitant to accept changes and they feel comfortable in unstructured environments. Therefore, there is a short to average duration of employment (Duanmu and Geppert, 2009) as employees may consider breaking company rules where it is for the good of the company (Hoecklin, 1995). People in this culture, therefore, tend to be more pragmatic and more tolerant of change.

\section{iii. Individualism (IDV) Vs Collectivism}

This dimension differentiates between cultures where emphasis is placed on the interest of the group over the desires of the individual and cultures where the desires of the individual come before that of the group (Hofstede, 1991:260). In effect, it is "the degree to which people in a country prefer to act as individuals rather than as members of groups" (Hofstede, 1993:89). Individualism refers to cultures where the bonds among members of society are loose and everyone is expected to look after their own interest and that of their family only. Members of such society tend to refer to themselves as "I" which recognizes their personal identity (Hofstede, 1991, 2005). In individualistic societies, therefore, the stress is put on personal achievements and individual rights and people are expected to stand up for themselves and their immediate family. On the other hand, in Collectivist cultures, the individual is expected to act predominantly as a member of a life - long and cohesive group. Interest of his or her collective first and the individual expects his or her collective to do the same for him or her.

In a business environment in individualistic cultures, employees perform best when they work on their own and appraisal of performance is based on individual initiative and achievement (Duanmu and Geppert, 
2005). In collectivistic cultures, employees performance tend to be high when placed in work groups which leads to belief in group decisions (Hoecklin, 1995). Here, there is emphasis on belonging to organizations, social and corporate, with the belief that such organizations will look after their best interest and defend them.

\section{iv. Masculinity (Mas) Vs Feminity}

This is the fourth dimension by Hofstede (1993) and it differentiates between characteristics that are considered to be traditionally masculine versus those that are considered to be traditionally feminine. That is, it distinguishes between societies where gender roles are sharply differentiated and clearly defined and those where gender roles overlap (Duanmu and Geppert, 2009). Masculinity refers to cultures where male roles are associated with assertiveness, performance, tough, and focus on material achievement and competition. Feminity refers to cultures where female roles are identified with more tenderness, modesty, caring for the weak, concern with the quality of life, and maintaining warm personal relationships ( Hofstede, 1991:90).

In the business environment, masculine cultures have fewer women in management positions and there is a large wage difference between genders as women generally are believed to belong to home taking care of children and not working in offices outside of the house (Hoecklin, 1995). In feminine cultures, managers are expected to use intuition and feelings when making decisions and so management positions are open to women. There is an emphasis rather than stiff competition which leads to less conflicts (Andrews and Mead, 2009).

\section{v. Long - Term Orientation Vs. Short Term Orientation}

This dimension was first called "conflucian dynamism". It describes societies in time horizon and focuses on the degree to which members of a culture have a long - term or short - term attitude towards all aspects of life (Firoz et al, 2002). Long - term orientation refers to cultures whose members are motivated by future rewadrds and they tend to drive and persevere in bad and uncomfortable situations (Hofstede, 2005). The outcome of this long - term orientation will be the acquisition of more skills and higher level competences that will prepare the employee for future opportunities. In short - term oriented cultures, on the other hand, people focus on the past and the present and have an eye on immediate results of situations. In the business contexts, short - term oriented cultures focus on the bottom line and want to be able to see an immediate positive outcome of an investment and long - term oriented cultures focus on building relationships and coordination as they believe these will lead to success in the long term ( Duanmu and Geppert, 2009).

\section{Rurak Dualism Cultural Model}

Dualism is from the Latin word duo meaning two. Dualism therefore denotes "a state of two parts". Dualism cultural model of Zbigniew T. Rurak in fact divided cultures into two interrelated and opposing categories. Rurak identified four types of dualities based on American and non - American cultures:

i.Contract Vs Trust: Contract based cultures such as America are legalistic, always codify societal arrangements on paper, and also expecting binding agreements to be on paper. This is to ensure contractual continuity. Many non - American cultures, Rurak argued, are less legalistic and less perfect in terms of contractual continuity. In such societies, he noted, even written contract is perceived as short lived. Trust, then is very important.

ii.Pragmatism and Ideology: Pragmatism means thinking about solving problems in a practical and sensible way rather than by having fixed ideas and theories. It is a practical approach to problems and centered on linking practice and theory. Ideology, on the other hand, refers to set of beliefs held by a person or a group that influences the way they behave. Rurak considers America as a highly pragmatic country as it has the reputation and drive to "go for it" and implement it, it organizes unhierarchically, quickly and effectively in teams and has the talent for implementation. But in contrast, Rurak pointed out, their foreign counterparts may have competing value systems or ideologies set deep in history. They seem rigid and brittle in their organizations, paternalistic, hierarchical in structure that more slowly and rarely "go for it"

iii.Individual Vs collectivity: The US, according to Rurak, "idolizes the rugged individual, the lonely, the resourceful entrepreneur and the intrepid iconoclast," and it concentrates power in both corporate and political life in the individual. Many other cultures, however, have established traditions of diffusing power and of shifting alliances among various participants. In these cultures, the existence of the group above the individual is more important (Rurak, 2012). 
iv.Social Darwinism Vs Homeostasis: Rurak (2012) explains that the US applauds competition and it makes efforts to attain desired change and growth, and that Americans have "an almost boundless faith in progress, improvement, and self - betterment". But to some other cultures, Rurak noted, stability and often longevity are synonymous with survival.

\section{The Iceberg Model Of Culture}

In order to explain and better understand the complex phenomenon called culture, some cultural sociologists and anthropologists (Hall, 1976; Weaver, 1986) have compared culture to an iceberg which has both visible (the surface or external) and invisible (below the surface) parts. The aspect that we can see above the water is tip of the iceberg and is referred to as the external or conscious or visible portion and the larger portion unseen and hidden beneath the surface of the water is called the internal or subconscious or invisible portion of culture.

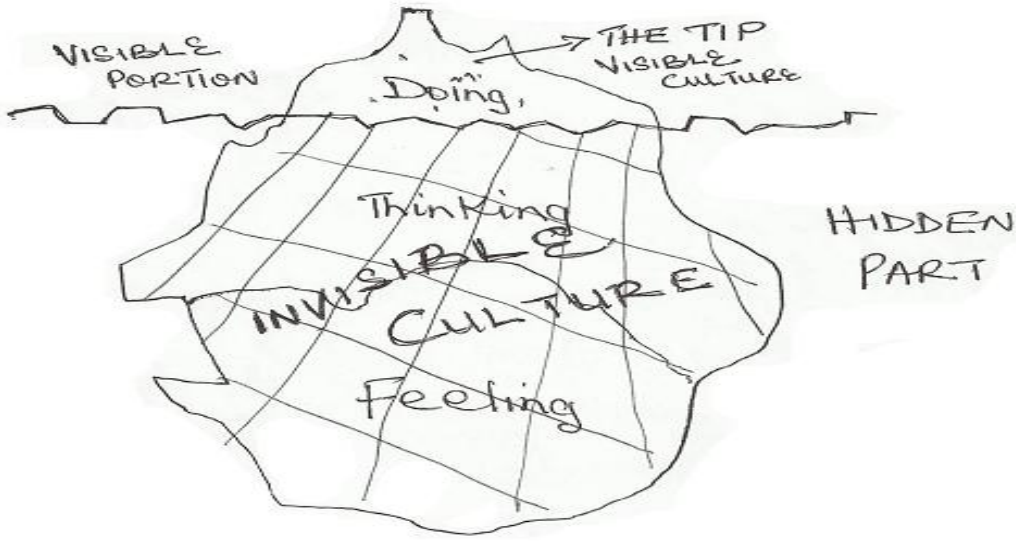

Figure 1: The iceberg model of cultures

Source: www. Cultures - class .com / index. php/cultural - concept, 1501/2013

The surface, conscious and visible portion of the iceberg consists of the elements of culture which are easily noticed and identified. They include language, arts, music, dance, dress, food, clothing, games, sports, architecture, gestures, cooking, religions, greetings, devotional practices, flags, festivals etc. The elements of culture in the larger internal, unconscious or invisible portion of the iceberg are those that are not so obvious. They include the concept of faith, sin, rules of relationships, importance of time, values, beliefs and attitudes, etiquette, norms, rules, concept of fairness, space arrangement etc.

Hall (1976) argued that there are major differences between the visible and invisible culture. The internal or invisible culture is implicit, learned, unconscious, difficult to change and a subjective knowledge, while external or visible culture is explicitly learned, it is conscious, easily changed and characterized by objective knowledge. To make sense of visible aspects of culture, Hall explained that you must understand the "invisible" underlying elements from which they originate. The only way to learn the internal culture of others is to actively participate in the culture of the outer culture or gain knowledge of the inner culture from research findings. This understanding can be of immense value to the international business manager.

\section{Kluckhohn And Strodtbeck Cultural Orientation Framework}

Kluckhohn and Strodtbeck (1961) developed an important value framework that helps to understand core cultural differences based on six basic human issues or concerns which they called value orientations. They argued that societies can be categorized along the six dimensions.

The six dimensions were described as follows:

- Relationship to nature. People have a need or duty to control or master nature (domination), to submit to nature (subjugation), or to work together with nature to maintain harmony and balance (harmony).

- Beliefs about basic human nature. People are inherently good, evil, or mixture of good and evil.

- Relationships among people. The greatest concern and responsibility as for one's self and immediate family (individualist), for one's own group that is defined in different ways (collateral), or for one's groups that are arranged in a rigid hierarchy (hierarchical).

- Nature of human's activity. People should concentrate on living for the moment (being), striving for goals (achieving), or reflecting (thinking). 
- Conception of space. The physical space we use is private, public, or a mixture of public and private.

- Orientation to time. People should make decisions with respect to traditions or events in the past, events in the present or in the future.

\begin{tabular}{|l|lll|}
\hline Dimension & & & \\
\hline Environment & Domination & Harmony & Subjugation \\
\hline Time Orientation & Past & Present & Future \\
\hline Nature of people & Good & Mixed & Evil \\
\hline Activity orientation & Being & Controlling & Doing \\
\hline Responsibility & Individualistic & Group & Hierarchical \\
\hline Conception of space & Private & Mixed & Public \\
\hline
\end{tabular}

Figure 2

SOURCE: $\quad$ Adapted from Kluckhon \& Strodtbek 1961

\section{The Benett Development Model Of Intercultural Sensitivity (Bdmis)}

Dr. Milton Benett $(1986,1993)$ created this model as a framework to explain the reactions of people to cultural differences after observing students over several months and sometimes years in intercultural workshops, classes, exchanges and graduate programmes (Cameroon sel by @ purdue. edu 8.02, 2012). He observed that in both academic and corporate settings individuals confronted cultural differences in some predictable ways as they learned to become more competent intercultural communicators (Bennett and Hammer, 1998). Bennett based is model on the assumption that the more experience a person has with cultural differences the more that person will develop intercultural competence, becoming more competent in intercultural relations and more effective when working across culture. Bennett, using concepts from cognitive psychology and constructivism, then organized his observations into a continuum of six stages of increasing sensitivity to cultural difference. He is of the view that each stage was indicative of a particular cognitive structure and that certain kinds of attitudes and behavior would typically be associated with each configuration of a worldview. The six stages move from "ethnocentrism" to enthnorelativism", meaning that one's own culture is experienced as central to reality in some way. They are:

Denial: This is the first stage. Individuals in this state deny that cultural differences exist and therefore are very unaware of cultural differences. They show no interest in discovering cultural differences and avoid other cultures by maintaining psychological and / or physical isolation from others. They may also act aggressively during cross cultural situations. The stage therefore represents the lowest degree of openness to cultural differences. Parochialism is a form of denial.

Defense: Whereas in the first stage of denial, individuals do not "see" cultural differences, in this second stage, they do perceive cultural differences. However, while individuals acknowledge the existence of certain cultural differences, but because those differences are threatening to their own reality and sense of self, the individuals construct defenses against those differences. They consider all other cultures to be inferior to their own culture and so they tend to be highly critical of those other cultures, regardless of whether the others are their hosts, their guests, or cultural newcomers to their society (Bennett and Hammer, 1998).

Minimization At this their stage of the model, individuals acknowledge cultural differences but will start believing that all cultures share common values, they still view many of their own values as universal, rather than simply as part of their own ethnicity. They therefore, try to minimize any cultural difference by correcting people to match their expectations: 


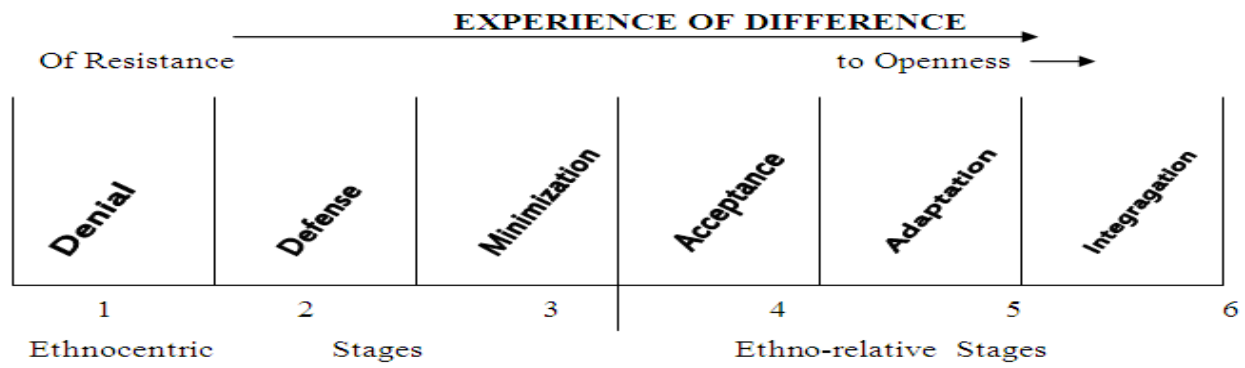

Figure 3: Development Model of Intercultural Sensitivity

Source: Milton Bennett, P. 19.

The second three stages of the model are ethno-relative, meaning that one's own culture is experienced in the context of other cultures.

Acceptance: This is the fourth stage of the DMIS model. This is the state in which people tend to recognize and value and accept cultural differences and see their own culture as one of a number of equally complex world views. They may become curious about and respectful toward differences. This stage moves an individual from ethnocentrism to ethno-relativism.

Adaptation: This is the fifth stage. At this state, there is perspective shifting as the individuals expand their own world view to include constructs from other world views. They gain the ability to look at the world "through different eyes" and adapt their behavior more easily and effectively by intentionally changing their own behavior to communicate more effectively in another culture, thus facilitating intercultural communication. The sixth and final stage of the Bennett model is referred to as integration. This stage requires in - depth knowledge of at least two cultures (One's own and another), and the ability to shift easily into the other cultural frame of reference and also deal with resulting identity issues. As the name of the stage implies, it involves the internalization of bicultural or multicultural frames of reference. Rising above the limitations of living in one cultural context, these individuals integrate aspects of their own original cultural perspectives with those of other cultures (http://www 2.ce.s.purdue.edu/iec/default.htm. Retrieved 18.08. 2012).

\section{Common Elements In Some Of The Theories Of Culture}

A close analysis of Geert Hofstede's dimensions of work - related values and Fons Trompenaars and Charles Hampden - Tuner's cultural dimensions and Edward T Hall's cultural continuum can lead to the development of an integrated framework of cultural dimensions (Throne and Saunders 2002). Three dimensions of Hofstedes's theory are similar to three dimensions from Trompenaars and Hampden - Tuner's model. Communitarianism Versus indivualism dimension of Trompenaars and Hampden - Tuner's model and the individualism and collectivism dimension of Hofstede's model can be identified as having a virtually identical relationship and this can also be closely linked to Hall's high and low context continuum. Also, similar to Hofstede's power distance dimensions is the achievement and ascription dimension of Trompnaars and Hampden - Tuner which, as stated earlier, describes how power and status is accorded. The rationale behind this similarity is the fact that if members of a society accept that power and status should be determined by nature and not achievements, then members of such society are also willing to accept an unequal distribution of power. Furthermore, a link can also be identified between Trompnaars and Hampden - Turners dimension of universalism versus particularism and Hofstede's dimension of uncertainty avoidance. In high uncertainty avoidance cultures, members of society tend to place emphasis on personal ties and relationships which is a match for particularism, and low uncertainty avoidance culture is a match for universalism as people from either of such society will not place too much emphasis on personal ties.In addition, Rurak's individuality vs collectivity duality is similar to Edward high context and low context cultures and Hofstede's individualism and collectivism dimensions and Kluckhohn's relationship among people concern.

Finally, Kluckhohn and Strodtbeck relationship to nature dimension is similar to Tramperaar and Truner's inner-directed vs outer-directed cultural dimensions and their time concern dimension similar to Hofstede's long - term and short - term Orientations. And Kluchohn and Strodtbeck's relationship among people dimension is similar to Edward's high and low context cultures, and Hofstede's individualism and collectivism Orientation.

\section{Conclusion}

The paper examined seven theories of culture, including Bennett's development of intercultural sensitivity, some common features of these theories are also highlighted. The other theories, besides Bennett's that were examined include Edward Hall's cultural continuum, Trompenaars and Hampden - Turner's cultural dimension, Hofstede's dimensions of work - related values, Rurak's dualities cultural model, the Ice-berg model of culture, and Kluckhohn and Stodtbeck cultural Orientations framework. An understanding of these theories or 
cultural lenses and their implications would help international business managers to become more culturally sensitive to cultural differences that could be great obstacles to prudent use of economic and human resources in a business enterprise, especially international business organizations that conduct business across cultural boarders. An in-depth-knowledge of these national theories will also enable international business managers to become culturally competent. Cultural competence implies development of sensitivity, awareness and understanding towards these different cultures. It is a set of congruent behaviours, attitudes and policies that come together in a system, agency or among professionals that enable effective work in cross-cultural situations (Paniagua \& Taylor, 2008, Sahar consulting, LLC., 2013). Thus understanding of the Surveyed national cultural models will enable the manager to acquire the required critical skills and become culturally proficient in working in multi-cultural or cross-boarder business environments.

\section{References}

[1]. Awesome Library (2012). "Stages of intercultural sensitivity". http//www/stages of-intercultural sensitivity (retrieved 20/08/2012).

[2]. Bennett, M. J. (2000). "Cultural marginality: Identity issues in intercultural training". In R. Michael Paige (Ed). Education for the Intercultural Experience. Yarmouth, M E: International Press.

[3]. Bennett, M. J. (1993). "Towards ethnorelativism: A developmental model of intercultural sensitivity". In R. M. Paige (Ed). Education for the intercultural experience. Yarmouth, M E: Intercultural Press.

[4]. Bennett, M. J. (1986). "A developmental approach to training for intercultural sensitivity". "International Journal of Intercultural Relations 10(2), $179-195$.

[5]. Bennett, Milton J and Hammer, Mitchell (1998): "The Developmental Model of Intercultural sensitivity". (http://www/Bennettdev/model/intercultural sensitivity. (Retrieved 19/07/2012).

[6]. Cultural - Sensitivity. http://www.kwintessential.co.uk/cultural-services/articles/cultural sensitivity in Business. Retrieved $21 / 08 / 2012$

[7]. Dewey, J. (1938). Logic: The theory of inquiry. New York: Henry Holt.

[8]. Duanmu, J. and Geeppert, M. (2009). International Business management (2 ${ }^{\text {nd }}$ Ed.) Irwin: McGraw-Hill.

[9]. Firoz, N. M., Kim, K. H. and Maghrahi, N. (2002). "Think globally, manage culturally". International Journal of cultural management, 12, (3\& 4) $35-50$.

[10]. Hall, Edward T. (1976). Beyond culture. New York: Anchor Books.

[11]. Hall, E. T. (1990) Understanding cultural differences. New York: Maine Intercultural Press Inc.

[12]. Hall, E. T. (1976). Beyond Culture. New York: Doubleday.

[13]. Hills, Michael D. (2002). “Kluckhohn and Stodtbeck's values Orientation theory” Online Readings in Psychology and culture, unit 4. Retrieved from http:// scholarworks.gvsu.edu/orpc/vol4/3 on 18th July, 2012.

[14]. Hills, Michael D. (2002). "Kluckhohn and Stodtbeck's values Orientation theory: Online readings in Psychology and culture, unit 4". Retrieved from http:// scholarworks.gvsu.edu/orpc/vol4 on 15/7/2012.

[15]. Hoecklin, L. (1995). Managing cultural differences: Strategies for competitive advantage. NY: Addision Wesley Publication.

[16]. Hofstede, G. (1993). "Cultural Constraints in management theories: The Academy of Management Executive, 31:81-94.

[17]. Hofstede, G and Hofstede, G. J. (2000): Cultures and Organizations: Software of the mind (3nd Ed) N Y: McGraw - Hill.

[18]. Hofstede, G. (2001) Cultures Consequences: Comparing values, behaviours, institutions and organizations across nations. London: Sage Publications.

[19]. Hofstede, G. (1996). Riding the waves of commerce: A test of Trompenaar's model of national culture differences" International Journal of Intercultural Relations, 20, 2:189-198.

[20]. Hofstede, G. (1994). "The business of international business is culture". International Business Review, 3, 1: 1-14.

[21]. Kim, D., Pan Y and Park, H. S. (1998). "High versus low context culture: A comparison of Chinese, Korean and American Cultures". Marketing and Psychology. 5, 16: $507-521$.

[22]. Kluckhohn, F. and Strodtbeck, F. L. (1961). Variations in value orientations. Evanston, Ill: Row Peterson.

[23]. Mead, R. (1998). International Management: Cross-cultural dimensions ( $2^{\text {nd }}$ ed.). Victoria: Blackwell Publishing

[24]. Mead, R. and Andrews, T. G. (2009). International Management (4 ${ }^{\text {th }}$ Ed.). West Sussex: John Wiley \& Sons Ltd.

[25]. Onkvisit, S. and Shaw, J. J. (1999). "Standardized International advertising: Some research issues and implications. Journal of Advertising Research, 19, 6:19-24.

[26]. Paniagua, C. T. \& Taylor, R. E. (2008). “The cultural lens of Genomics”. The Online Journal of Issues in Nursing (OJIN), 13, 1 (Manuscrip 5, Jan.)

[27]. Purdue University (2012): International Extension Curriculum: Strengthening Extension's capacity for international Engagement. Lecture Units 1, 2, 3 on the Bennett Developmental Model of Intercultural Sensitivity. http://www2.ce.s.purdue.edu/ice/ default.htm. Retrieved on 18/08/2012.

[28]. Sahar Consulting, LLC. (2013). Cultural competence training. www.saharconsulting. Com/pages/cultural/competence retired $30 / 03 / 2013$.

[29]. Thorne L. and Saunders, B. S. (2002). The Socio-cultural embeddedness of individuals ethical reasoning in organizations (Crosscultural ethics)".Journal of Business Ethics, 35:1-14.

[30]. The Iceberg-model-of-culture. http://blog.communical .com/cross-cultural-training -Retrieved 13/09/2012.

[31]. Trompenaars, F. and Hampden - Turner, C. (1997). Riding the waves of culture: Understanding cultural diversity in business $\left(2^{\text {nd }}\right.$ ed.) London: Nicholas Brealey Publishing Tzeremes, N. G. and Halkos, G. E. (2008). Does the home country's national culture affect MNC's performance? Empiral evidence of the world's top 100 East - West non - financial MNC's". Global Economic Review, 37, $4: 405-427$.

[32]. UNFPA (2013) Population issues: Cultural sensitive approaches. www.unfpa.org/culture/culture.thm. Retrieved 30/03/13.

[33]. Weaver, G. R. (1986). "Understanding and coping with Cross-cultural Orientations: New Conceptualizations and applications. Lanham, M. D.: University Press of America. 